\title{
QUESTIONNAIRE
}

Date

Internal Number:

Laboratory:

Process number:

\section{Personal data}

Residence:

Level of education:

Age: Gestational Age:

Number of births

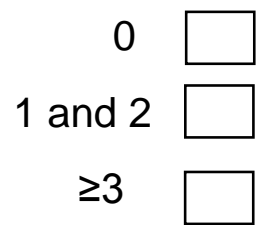

Did you do prenatal consultation in all pregnancies?

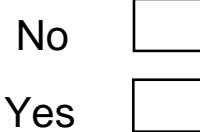

\section{Risk factors}

1. Have you ever done a toxoplasmosis test?

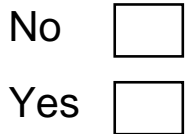

If yes what was the result? positive

negative

\section{Awareness of toxoplasmosis?}

Do not you know anything about the disease?

It has hear spoken, but does not know anything about it

Do you know anything about the disease 
3. In the residence, do you have a basic sanitation? (water treated, collection refuse, sewage system):

Yes $\square$

No $\square$ If not, which one do not have?

Water treated

Collection refuse

Sewage system

4. Do you currently have pets at home?

No

Yes $\square$

If so, which?

Cats

Dogs

Others
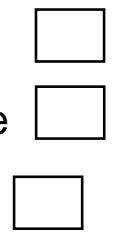

5. Currently has contact with animals other than yours at home the of relatives or other households?

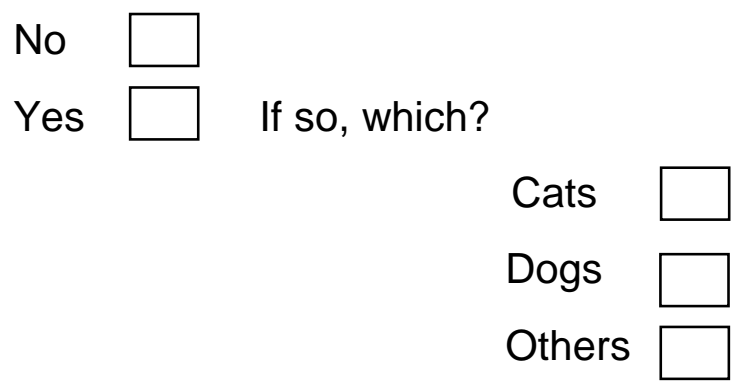

6. Do you have contact with cats other than yours?

No $\square$
Yes $\square$

If so, how often?

Very frequent

Less frequent

Rarely

7. In the case you have pet cats, where do they defecate?

Inside home

In the vicinity of the house

Far from the house

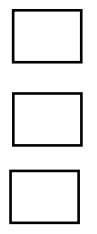


8. If you have pet cats, what is your main food?

Ration

Leftover food (cooked)

Leftover Raw Meat

9. Do you know of rodents at or near your home?

No $\square$

Yes $\square$

10. Do you have a garden in your residence?

No $\square$

Yes $\square \quad$ In the case of yes this is fenced, preventing the entry of cats

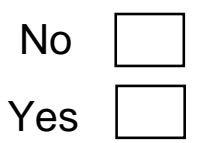

11. Do you carry out soil-related activities (gardening, agriculture, etc.)?

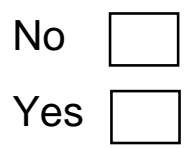

12. Do you have farmed animals for your own consumption?

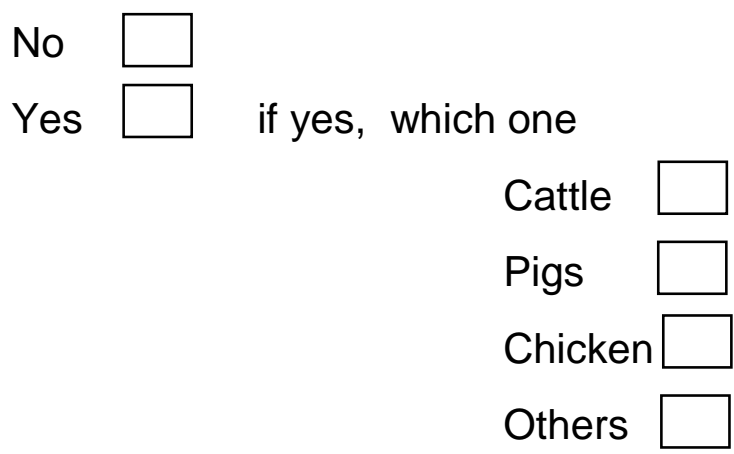

12. Do you have habits of consuming meat from hunting animals such as birds, rabbits, wild boars etc.

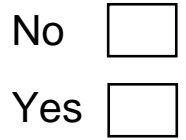


13. Do you eat raw or undercooked meat?

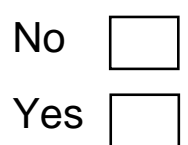

if yes, from which animals?

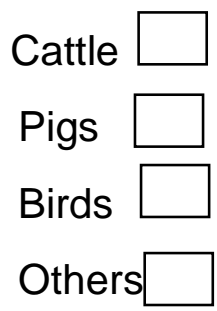

if yes, how often?

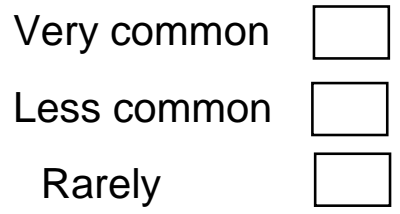

14. Do you consume unpasteurized milk or dairy products?

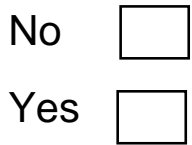

if yes, how often?

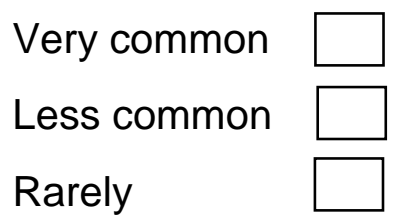

15. Do you always wash fruits and vegetables before consuming them?

No

Yes

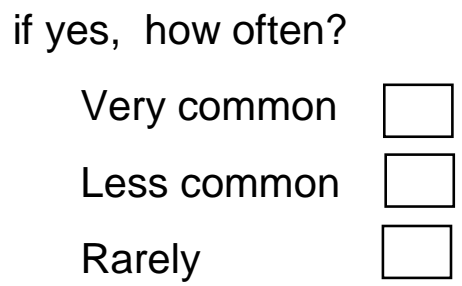

16. Do you eat raw or undercooked eggs?

No $\square$

Yes $\square$

if yes, how often?

Very common 


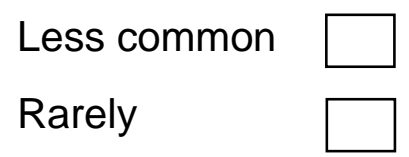

17. Do you consume water from borehole?

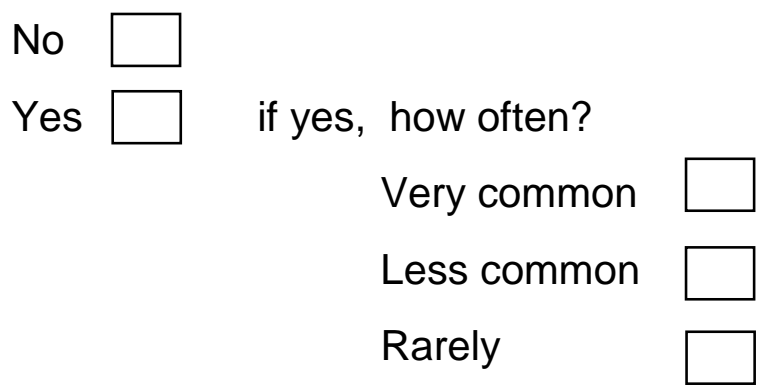

18. Have you recently had a blood transfusion?

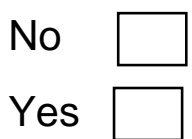

19. Recently had you a needle stick / syringe accident?

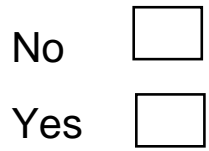




\section{Questionário de Recrutamento}

Data

Número interno:

Laboratório:

Número do Processo:

Dados Pessoais

Residência:

Nível de escolaridade:

Idade:

Idade Gestacional:

Quantas vezes já esteve grávida?

Uma

Duas

Mais

Fez consulta pre - natal em todas as gestações?

Não

Sim

Factores de risco

\section{Alguma vez fez o teste de toxoplasmose?}

Não

Sim

Se sim qual foi o resultado? positivo

negativo

\section{Conhecimento da doença?}

Desconhece

Já ouviu falar mas não sabe nada a respeito

Sabe alguma coisa sobre a doença 
3. Na residência, possui saneamento básico? (água tratada, colheita de lixo, sistema de esgoto):

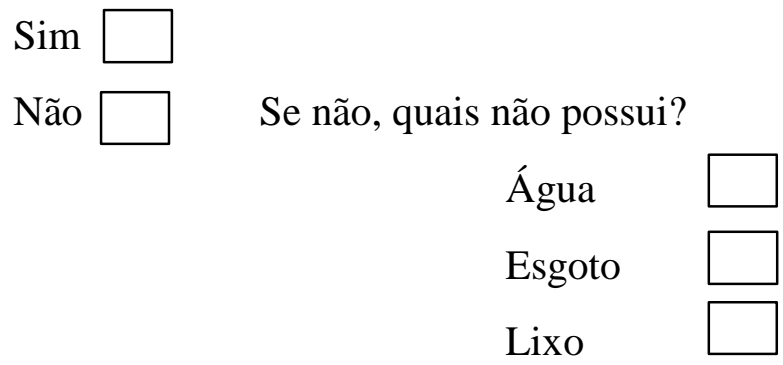

4. Tem animais de estimação actualmente em casa?

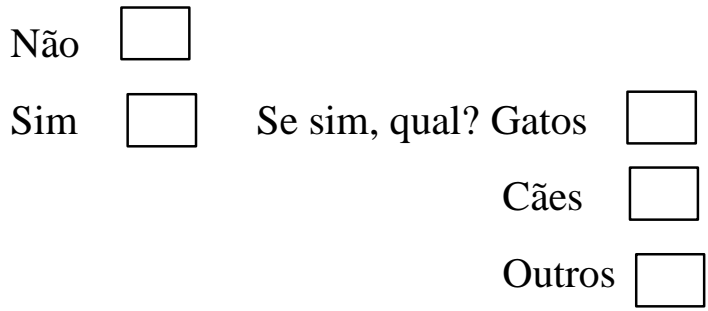

Qual é o número destes animais no domicílio?

Os animais têm acesso ao interior de sua residência?

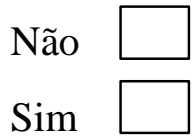

5. Atualmente tem contacto, com frequência, com animais, que não os seus, em casa de parentes ou outras residências?

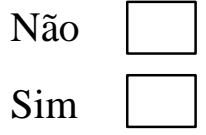

Se sim, quais? Gatos

Cães

Outros

6. Tem contacto com outros gatos que não sejam os seus?

Não

Sim

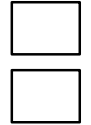

Se sim com que frequência?

Muito frequente

Pouco frequente

Raramente

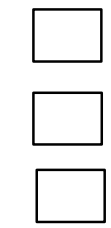


7. Caso tenha gatos de estimação, onde é que eles defecam?

Dentro da casa

Na proximidade da casa

Distante da casa

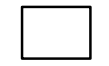

8. Caso tenha gatos de estimação, qual é o seu principal alimento?

Ração

Restos de comida (cozinhada)

Restos de carne crua

9. Sabe da existência de roedores no seu domicílio ou nas proximidades?

Não

Sim

10. Tem horta na sua residência?

Não

$\operatorname{Sim} \square$

Se sim esta é cercada, evitando a entrada de gatos?

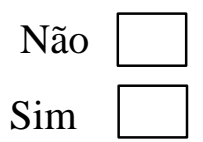

11. Realiza atividades ligadas ao solo (jardinagem, agricultura, etc.)?

Não $\square$

$\operatorname{Sim}$

12. Tem animais de criação para consumo próprio?

Não $\square$
$\operatorname{Sim} \square$

Se sim, quais?

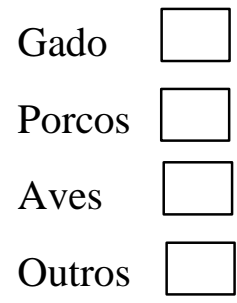


12. Tem hábitos de consumir carne proveniente de animais abatidos em caça como pássaros, coelhos, javalis etc.

Não

Sim

13. Consome carne crua ou mal cozida?

Não

$\operatorname{Sim} \square$

$$
\begin{array}{ll}
\text { Se sim, de que animais? } & \text { Gado } \\
& \text { Porco } \\
& \text { Ave } \\
& \text { Outros }
\end{array}
$$

Se sim, com que frequência?

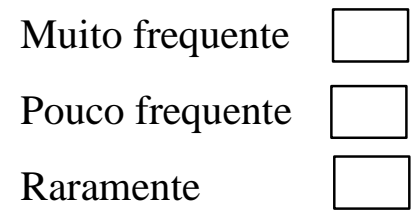

14. Consome leite ou lacticínios não pasteurizados?

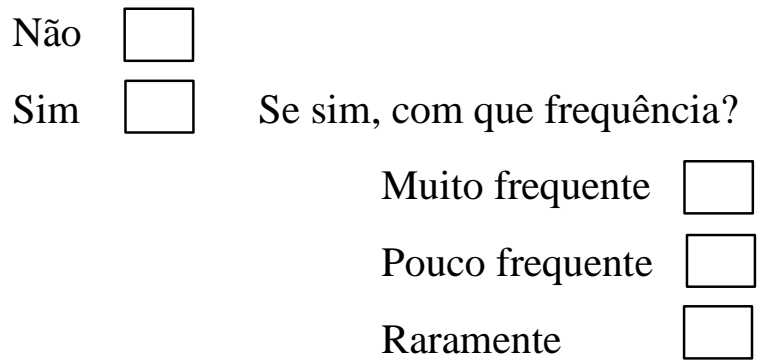

15. Lava frutas e verduras sempre antes de consumi-las?

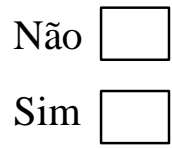

Se sim, com que frequência?

Muito frequente

Pouco frequente

Raramente

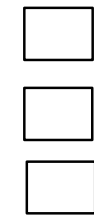


16. Consome ovo cru ou mal cozido?

Não

Sim

Se sim, com que frequência?

Muito frequente

Pouco frequente

Raramente

17. Consome água de poço/furo?

Não

Sim $\square$ Se sim, com que frequência?

Muito frequente

Pouco frequente

Raramente

18. Recentemente fez alguma transfusão de sangue?

Não

Sim

19. Recentemente teve alguma picada/acidente de agulha/seringa?

Não $\square$
Sim $\square$ 


\section{Questionário de Recrutamento}

Data

Número interno:

Laboratório:

Número do Processo:

Dados Pessoais

Residência:

Nível de escolaridade:

Idade:

Idade Gestacional:

Quantas vezes já esteve grávida?

Uma

Duas

Mais

Fez consulta pre - natal em todas as gestações?

Não

Sim

Factores de risco

\section{Alguma vez fez o teste de toxoplasmose?}

Não

Sim

Se sim qual foi o resultado? positivo

negativo

\section{Conhecimento da doença?}

Desconhece

Já ouviu falar mas não sabe nada a respeito

Sabe alguma coisa sobre a doença 
3. Na residência, possui saneamento básico? (água tratada, colheita de lixo, sistema de esgoto):

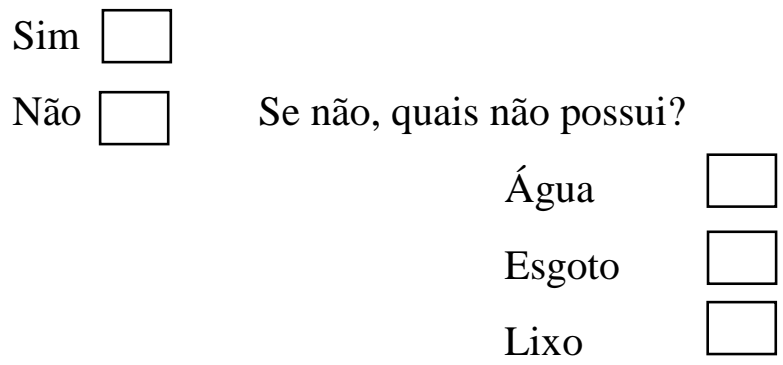

4. Tem animais de estimação actualmente em casa?

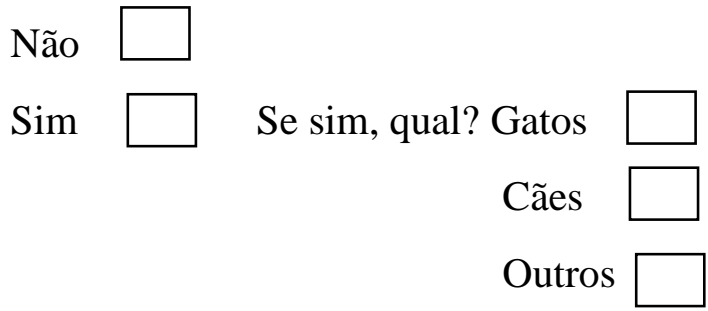

Qual é o número destes animais no domicílio?

Os animais têm acesso ao interior de sua residência?

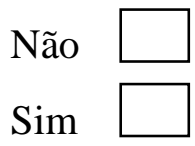

5. Atualmente tem contacto, com frequência, com animais, que não os seus, em casa de parentes ou outras residências?

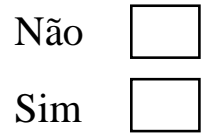

Se sim, quais? Gatos

Cães

Outros

6. Tem contacto com outros gatos que não sejam os seus?

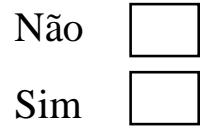

Se sim com que frequência?

$$
\begin{aligned}
& \text { Muito frequente } \\
& \text { Pouco frequente } \\
& \text { Raramente }
\end{aligned}
$$

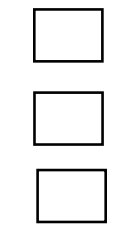


7. Caso tenha gatos de estimação, onde é que eles defecam?

Dentro da casa

Na proximidade da casa

Distante da casa

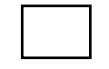

8. Caso tenha gatos de estimação, qual é o seu principal alimento?

Ração

Restos de comida (cozinhada)

Restos de carne crua

9. Sabe da existência de roedores no seu domicílio ou nas proximidades?

Não

$\operatorname{Sim}$

10. Tem horta na sua residência?

Não

$\operatorname{Sim} \square$

Se sim esta é cercada, evitando a entrada de gatos?

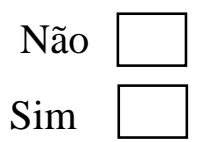

11. Realiza atividades ligadas ao solo (jardinagem, agricultura, etc.)?

Não $\square$

Sim

12. Tem animais de criação para consumo próprio?

Não $\square$
$\operatorname{Sim} \square$

Se sim, quais?

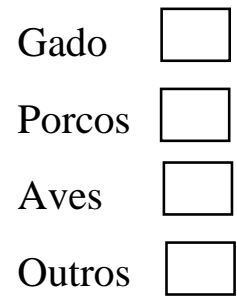


12. Tem hábitos de consumir carne proveniente de animais abatidos em caça como pássaros, coelhos, javalis etc.

Não

Sim

13. Consome carne crua ou mal cozida?

Não

$\operatorname{Sim}$

Se sim, de que animais?

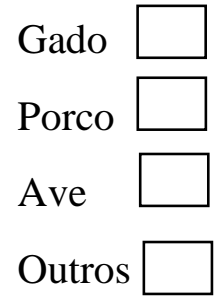

Se sim, com que frequência?

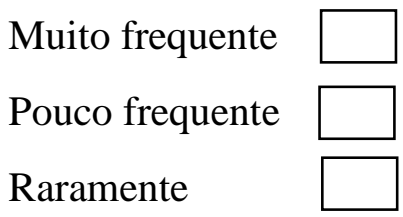

14. Consome leite ou lacticínios não pasteurizados?

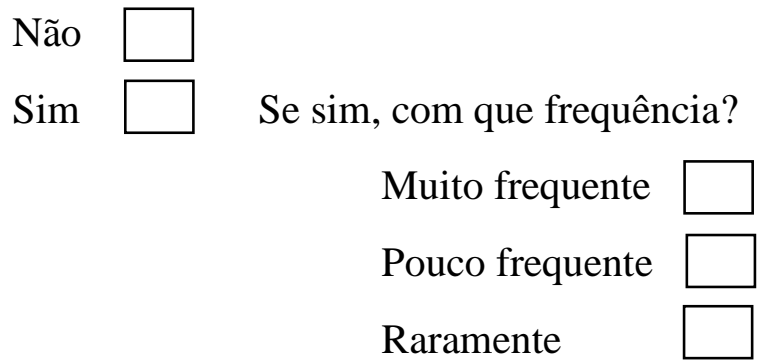

15. Lava frutas e verduras sempre antes de consumi-las?

Não

Sim

Se sim, com que frequência?

Muito frequente

Pouco frequente

Raramente

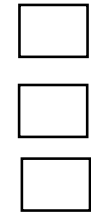


16. Consome ovo cru ou mal cozido?

Não

Sim

Se sim, com que frequência?

Muito frequente

Pouco frequente

Raramente

17. Consome água de poço/furo?

Não

$\operatorname{Sim} \square$ Se sim, com que frequência?

Muito frequente

Pouco frequente

Raramente

18. Recentemente fez alguma transfusão de sangue?

Não

Sim

19. Recentemente teve alguma picada/acidente de agulha/seringa?

Não

Sim 